\title{
A PERSPECTIVA SOCIOCULTURAL E AS INTERACÇÕES LÚDICAS NOS PRIMEIROS ANOS DA INFÂNCIA: REVENDO CONTRIBUI PÕES
}

\author{
THE SOCIOCULTURAL PERSPECTIVE AND PLAYFUL \\ ACTIVITIES INTERACTIONS IN THE EARLY YEARS OF \\ CHILDHOOD: REVIEWING CONTRIBUTIONS
}

Maria de Fatima Aranha de Queiroz e Melo*

Queiroz e Melo MFA. A perspectiva sociocultural e as interações lúdicas nos primeiros anos da infancia: revendo contribuições. Rev Bras Cresc Desenv Hum 2004;14(2):44-49.

Resumo: Neste artigo, examinamos algumas contribuições da visão sociocultural para a temática do lúdico, com ênfase nas primeiras relações estabelecidas pelos bebas com seus contextos culturais, através de seus cuidadores. Para tanto, torna-se necessário abordar sucintamente a concepção de zona de desenvolvimento proximal, assim como as considerações sobre o brincar na qualidade de uma interação social, altamente privilegiada, desde cedo experienciada, que se constitui em alicerce para a construção de aprendizagens bastante sofisticadas ao longo da vida.

Palavras-chave: Zona de desenvolvimento proximal. Brincadeira de faz-de-conta. Interações lúdicas mãe-bebê.

\section{INTRODUÇÃO}

Sem a intenção de excluir outras contribuições relevantes para esta temática, utilizamos a perspectiva sociocultural como a norteadora da maior parte das discussões que empreenderemos neste artigo, tomando o conceito de Zona de Desenvolvimento Proximal, formulado por Vygotsky $^{1}$, como um dos eixos para as nossas considerações. Este conceito preconiza o desenvolvimento em níveis: real (que é o que o sujeito consegue realizar sem ajuda externa, a partir do que já conquistou) e o potencial (que o sujeito realiza com a ajuda de um outro mais experiente), sendo o espaço entre estes dois níveis uma zona de construção de aprendizagens. Vygotsky ${ }^{1}$ opera com a idéia de que o processo de desenvolvimento das aprendizagens tem um percurso que vai de níveis menos complexos até níveis mais complexos e pressupõe a interação entre sujeitos ingeridos em contextos sócio-históricos determinados, sendo estas trocas sociais a alavanca para atingir os níveis de aprendizagem ainda não alcançados.

O brincar foi observado por Vygotsky ${ }^{1}$ como uma atividade de origem sociocultural através da qual a criança vive desafios para além de seu comportamento atual, elabora regras e papéis sociais, vive um enredo ou situação imaginária em que se comunica e atribui significados diversos às ações e aos objetos. Para Vygotsky ${ }^{1}$, o brincar tem sua origem na situação imaginária criada pela criança, na qual desejos podem ser realizados, reduzindo a tensão e acomodando os conflitos e as frustrações da vida real, além de ser um processo de trocas humanas altamente específico e privilegiado de mediatização em uma cultura. Nas brincadeiras, podemos verificar a imitação e representação de papéis sociais num jogo síciodramático em que as crianças utilizam objetos substitutos, vivem e elaboram regras num processo de negociação intensa com o mundo físico e o mundo social. O jogo simbólica tem a prerrogati-

Professora do Departamento de Psicologia da Universidade Federal de São João dei Rei e membro do LAPIP (Laboratório de Pesquisa e Intervenção Psicossocial) do DPSIC/IJFSJ. Mestre em Educação pela PUC-Rio; doutorando do Programa de Pósgraduação em Psicologia Social da Universidade Estadual do Rio de Janeiro, e-mail: queirozmaldos@mgconecta.com.br 
va de possibilitar a transição de coisas como objetos de ação para coisas como objetos de pensamento, sendo a origem dos processos de abstração dos adultos já que são dados os primeiros passos para o descolamento do real imediato.

Vygotsky ${ }^{1}$ postula três características presentes em qualquer tipo de brincadeira, seja a brincadeira de "faz-de-conta”, tradicional, ou de regras: a imaginação, a imitação e a regra. Na criança pequena, a porção de imaginação é maior e as regras estão implícitas, mas à medida em que a criança cresce, as regras vão ficando mais explícitas e a situação imaginária vai declinando. A partir dessas características, a brincadeira cria uma “zona de desenvolvimento proximal”, um espaço de experimentação que auxilia a criança na superação de seus níveis reais de desenvolvimento. Nesta experiência, as crianças vivem o dilema entre a liberdade de brincar e a submissão às regras, o desejo versus a realidade. Pela vivência desses conflitos, elas enriquecem tanto a relação interpessoal, como as suas aprendizagens. $\mathrm{O}$ papel dos pares e dos adultos torna-se fundamental neste processo porque propicia às crianças confrontar seus pontos de vista, rever a adequação de suas estratégias atuais, negociar formas inéditas de comportar-se, na brincadeira ou no jogo, assim como experimentar novas maneiras de atuar oferecidas pelos companheiros mais experientes, sejam estes crianças ou adultos.

\section{As trocas lúdicas nos primeiros meses de vida}

A perspectiva sociohistórica aponta para o fato de que, desde o nascimento, a criança está imersa em um contexto social, desenvolvendo-se através das interações que estabelece, muito cedo, com a experiência dos adultos e do mundo por eles criado. A brincadeira seria uma forma de introduzir a criança neste mundo, constituindo-se um modo de assimilar e recriar a experiência sóciocultural dos adultos (Wajskop², 2001, p. 25).

Pesquisas recentes sobre os primeiros anos de vida mostram como as crianças, mesmo em idade muito precoce, são capazes de interagir de maneira eficaz, controlando e regulando o comportamento de parceiros adultos em relações diádicas assimétricas. Ampliando com o tempo suas possibilidades de ação a outros parceiros não adultos, os bebês desenvolvem interações simétricas com pares, favorecendo a construção de competências de várias ordens. Seja pelo confronto, seja pela cooperação, esses progressos ocorrem dentro de um espaço de trocas caracterizado pelo que Vygotsky chamou de Zona de Desenvolvimento Proximal.

Seidl de Moura e Ribas ${ }^{3}$ (2000) estudam as interações entre adultos (especialmente as mães) e bebês como um campo de grande fertilidade, ressaltando que as pesquisas empíricas ainda não oferecem uma implicação teórica adequada, até porque esta área de estudos está longe de atingir seu esgotamento, dada a quantidade de esforços que estão sendo desenvolvidos neste sentido. Apoiando-se em autores da perspectiva sóciointeracionista, a autora busca uma compreensão desta interação inicial em termos de sua repercussão na ontogênese, situando-a na condição de uma atividade mediada. Para atividade mediada, toma a definição de Wertsch ${ }^{4}$ (1995) como uma “ação humana realizada por um indivíduo ou grupo que emprega um artefato cultural ou meios de mediação”(p. 89). É através destas interações sociais que se faz a mediação nas trocas realizadas no plano social, externo ao indivíduo, para que depois haja uma internalização a partir de processos de apropriação particulares.

Vygotsky ${ }^{l}$ (1984) faz referência a vários tipos de brinquedo, mas discute com grande ênfase o papel da brincadeira de "faz-de-conta" no desenvolvimento infantil, por propiciar, através de uma situação imaginária, a inserção numa atividade regida por regras em que a criança se comporta de uma forma mais avançada do que nas atividades na vida real, permitindo a separação entre objeto e significado, possível apenas a crianças que tiverem desenvolvido a capacidade de simbolização.

Entretanto, segundo Garvey apud Bondioli \& Mantovani ${ }^{5}$ (1998 p. ), que estudou o desenvolvimento dos papéis da dupla mãe-bebê no jogo infantil de 18 meses a 3 anos, a brincadeira de faz-de-conta, na qualidade de um jogo infantil, evolui a partir de formas muito precoces, antes do término do primeiro ano de vida, enquanto um movimento de descoberta, de exploração do mundo. Este movimento que explora um mundo que inclui os objetos apresentados à criança pelos mediadores de sua cultura se complexifica posteriormente para o jogo simbólico propriamente dito, quando a criança vai tornar-se capaz de evocar os objetos na sua ausência, marcando o início de uma função representativa.

A brincadeira de "faz-de-conta" é privilegiada porque promove a passagem de uma situação de fusão entre objetos e significados para uma situação em que se torna possível a elaboração destes elementos. No caso do bebê, entendemos este brincar de faz-de-conta como toda uma série de comportamentos exploratórios do seu próprio corpo e do corpo da mãe, numa tentativa de conhecimento de si e do mundo para construir-se progressivamente através das trocas que realiza com o ambiente. Na situação imaginária do brincar, há um descolamento do real imediato e pre- 
sente, constituindo-se um passo importante no percurso que levará a criança a ser capaz de desvincular-se totalmente das situações concretas. Segundo Bondioli e Mantovani ${ }^{5}$ (1998), o jogo do faz-de-conta, até mesmo nas suas fases embrionárias, tem um importante papel nas trocas emocionais e afetivas, não somente no conhecimento e na descoberta do mundo dos objetos, mas como estratégia de controlar, elaborar, tornar previsível um mundo que a criança ainda não é capaz de identificar.

Brougère $^{6}$ (2002) discute as brincadeiras de bebês com suas mães como um dos lugares essenciais da aprendizagem da cultura que preexiste e define o jogo, tornando-o possível nas formas solitárias que assumirá posteriormente. E nesse lastro cultural, que a criança vai assimilar cada atividade lúdica em suas versões mais personalizadas. Segundo Brougère ${ }^{6}$ :

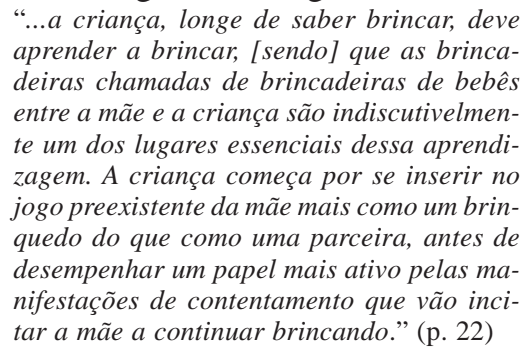

Uma parceria desajeitada pela imitação da mãe vai se constituindo a seguir, nas brincadeiras de esconder uma parte do corpo, em que a criança nos dá sinais de que reconheceu algumas das características essenciais do jogo: o aspecto fictício do jogo do faz-de-conta, já que o corpo não desaparece de verdade; a repetição infindável da brincadeira, já que não há, de fato, uma modificação da realidade e sempre pode-se voltar ao início.** Podemos ver, na alusão de Brougère ${ }^{6}$, uma versão embrionária do jogo do faz-de-conta na interação entre mãe e bebê. A inversão de papéis e um acordo entre parceiros são também características do jogo aprendidas pelas crianças, um pouco mais adiante, em seu desenvolvimento, através das brincadeiras, marcando o seu aspecto fundamentalmente social.

Froebel 1912 apud Kishimoto ${ }^{7}$ (2002 p. 75) chama a atenção para o jogo como fator de desenvolvimento integral das possibilidades da criança, dentro da sua condição de organismo biológico-social. Ao brincar, a criança expressa com liberdade as suas tendências internas, prestandose o jogo a dois objetivos: um fim em si mesmo (autoexpressão, espontaneidade) e um meio de ensino (busca de algum resultado). Embora de 1883, traduzida pelo título Canções à Mãe, Froebel intui o papel da imitação nas brincadeiras interativas entre a mãe e a criança pequena, resgatando brincadeiras integrantes do repertório de práticas lúdicas tradicionais alemãs. Nesta obra, que trata dos movimentos, das canções, dos poemas e do papel da mãe na educação da primeira infância, Froebel aponta as brincadeiras interativas da criança com a mãe como sua primeira expressão, seu primeiro ato de fé, seu primeiro insight, que evoluirá em conhecimento e que deverá, portanto, ser estimulado. Em outro livro, Música e Jogos da Mãe, Froebel percebe que, por meio de brincadeiras interativas com os adultos, é possível ensinar a linguagem à criança devido a uma estreita relação entre a linguagem, a descoberta da regra e o contexto, nas brincadeiras de esconde-esconde entre o bebê e a mãe.

"Ao observar mães brincando com seusfilhos, Froebelpercebe que elas associam objetos com palavras mas não percebem a iniciativa da crian,ca. Assim, por meio de seus brinquedos e dons, criam 0 espanco para a crian,ca ter iniciativa, expressar sua fala, representar seu imaginário.”

(Kishimoto ${ }^{7}, 2002$, p.75).

A incessante experimentação das propriedades dos materiais, dos objetos e das ações realizadas pelo bebê, enquanto um jogo, oferecem uma oportunidade para tentar novas combinações que vão sendo aplicadas à realidade, à semelhança de um esquema gerador de possibilidades (Bruner $\left.{ }^{9}, 1972\right)$. Trata-se de uma experimentação que está assentada no conjunto de trocas sociais e que mais tarde lançará as bases para os processos mais elaborados, inclusive o da aquisição da linguagem.

A curiosidade infantil se constitui a partir de situações sociais compartilhadas com os adultos que funcionam como intermediários em relação aos eventos do mundo físico e social, sendo o jogo/a brincadeira um espaço onde se constrói uma experiência compartilhada com base nos modelos culturais disponíveis.

Rochat e Striano ${ }^{10}$ (1999), ao estudarem a cognição social nos primeiros meses de vida, colocam que a capacidade de projetar experiências compartilhadas em outros contextos é um mecanismo instrumental, havendo um possível elo de

\footnotetext{
* * Este poder voltar sempre ao início é também mencionado por Benjamin (1984) como uma lei fundamental que rege totalidade do mundo do brinquedo que é a lei da repetição. O "mais uma vez” ou "de novo" que traduz o ímpeto obscuro pela repetição é tão poderoso na criança que deseja tornar-se senhora de suas experiências primordiais, como o é para o adulto quando narra suas experiências de horror ou felicidade, na busca de elaboração do vivido.
} 
ligação entre a nossa filogênese e a nossa ontogênese, na medida em que as espécies de primatas mais próximas do gênero humano também apresentam um comportamento empático. Devido a um estado de imaturidade prolongada que caracteriza a infância humana, há grande necessidade de manter uma relação de proximidade com seus cuidadores por parte dos bebês. Esta experiência compartilhada, ou o que os autores chamam de intersubjetividade, que se desenvolve na infância, no contexto íntimo das interações face-a-face, é o fundamento da cognição social. É o que permite aos bebês monitorar e predizer o comportamento daqueles de quem dependem.

Rochat e Striano ${ }^{10}$ (1999) também defendem que essa intersubjetividade primária nos bebês, necessária para o desenvolvimento de toda cognição avançada e que lhes dá a oportunidade de coordenar sua experiência de mundo privado com o mundo de outros, teria base nas experiências subjetivas (sentimentos, afetos, emoções) que fariam eco nos sentimentos, afetos e emoções dos outros, nas interações em que as partes se engajam numa co-regulação emocional. As experiências compartilhadas com os adultos nas interações face-a-face, ou nos jogos verbais, seriam a fonte de toda a intersubjetividade. Aí, nesse espaço de trocas face-a-face compartilhadas entre adultos e bebês, que o lúdico desenvolveria um papel fundamental. É particularmente no sistema de interações lúdicas entre adultos e bebês, como nos jogos de "vou te pegar", de "cadê?/ achou!" (forma embrionária da brincadeira de esconde-esconde), que verificamos como os afetos, sentimentos e emoções de um repercutem nos afetos, emoções e sentimentos de outro, numa dinâmica de coregulação emocional. Segundo os autores, antes mesmo do aparecimento da linguagem, que permite à criança comunicar e coordenar sua experiência privada com a de outros, estes jogos não verbais, diádicos, face-a-face se constituem como fonte primária de intersubjetividade.

Segundo Rochat e Striano ${ }^{10}$ (1999), a idade de dois meses marca um ponto do desenvolvimento em que as interações entre bebês e cuidadores tornam-se mais prazerosas e lúdicas devido à reciprocidade surgida entre ambos, ultrapassando meras rotinas de alimentação e acalmamento. Essas rotinas proporcionam um campo dinâmico de observação para os bebês, permitindo-lhes perceber invariantes do mundo social que vão além dos atributos físicos: tempo de reação, dinâmica de vida, tônus global de postura, elementos das pessoas que dizem ao bebê sobre mundo, sobre outros e sobre ele próprio. O valor lúdico dessas rotinas ou rituais (interações face-a-face, gestos e palavras trocados na hora das refeições, do banho ...) permite ao bebê uma certa previsibilidade dos eventos, promovendo um efeito tranqüilizador diante de um mundo desconhecido e dando-lhe a oportunidade de desempenhar um papel mais ativo nessa relação. Para os autores, é a partir deste ponto que podemos falar de cognição social ou intersubjetividade.

Os nove meses, segundo Rochat e Striano ${ }^{10}$ (1999), marcam uma etapa em que os bebês apresentam um progresso significativo na cognição social através do desenvolvimento de competências sociais triádicas e da intersubjetividade secundária. As competências triádicas significam a habilidade de monitorar os outros na sua relação com objetos. A atenção conjunta ao mundo físico, a coordenação de sua própria perspectiva com a dos outros pela comunicação gestual e pelo olhar que segue os movimentos são indicadores para a construção da intersubjetividade secundária por volta dos 9 meses, tornando possível ensinar e aprender. Entre as crianças e as mães que acompanham os seus interesses para o mundo ao redor, ocorre uma sincronia de olhares, de forma que através da ênfase gestual e/ou vocal, o adulto acaba direcionando a atenção do bebê para aspectos do ambiente que considera relevantes. Com relação ao papel de mediador do adulto, Bondioli e Mantovani ${ }^{5}(1998)$ levantam as considerações de Newson e Newson ${ }^{11}$ (1979), apontando os jogos interativos com bebês que tomam a forma de triálogos:

“A mãe amplia o próprio diálogo com a criança até incluir o brinquedinho, alternando de maneira rítmica a voz, o gesto (por exemplo, balançar um chocalho) e a intervenção da criança (por exemplo vocalização, olhar) de maneira a deslocar a atenção da criança do próprio rosto ou das próprias mãos ao objeto. Através dessa função mediadora do adulto, o diálogo mãe-criança transforma-se em conversação a três, na qual o brinquedo é dotado daquele mesmo caráter de "prontidão de resposta" que caracteriza o parceiro humano.” (p. 217).

Daí em diante, a tendência é de que a criança sozinha se oriente em relação aos aspectos do mundo que lhe são atraentes com uma progressiva retirada da figura da mãe.

\section{As trocas lúdicas nos primeiros anos da infância}

Descentrando-se da figura do adulto cuidador mais presente nos primeiros meses de vida, a criança achará outros parceiros nas suas atividades lúdicas, à medida que vai ampliando suas capacidades de inserção e interação com/ no o meio físico e social pela própria condição de amadurecimento biológico, assim como pelo resultado das experiências desenvolvidas na relação com seus cuidadores Especialmente nos jogos de faz-de-conta, os parceiros vão of erecer, 
na maior parte das vezes, estímulos e temáticas diferenciados daqueles oferecidos pela mãe ou cuidadora.

Segundo Tamis-Le Mondaet al. ${ }^{12}$ (2002), as brincadeiras de faz-de-conta entre pares vão introduzir componentes de aventura, exploração e até de elaboração da realidade, quando as partes envolvidas na brincadeira estiverem numa condição de compartilhamento de situações que lhes causaram grande impressão. Estes autores analisaram as funções do jogo infantil nos primeiros anos da infância, à luz do papel exercido pelos parceiros mais experientes (crianças mais velhas ou adultos), chamando a atenção para a natureza mutante dessas funções, tal como para o papel exercido pelos parceiros. De uma maneira geral, o brincar com adultos e com crianças mais velhas propicia inúmeros ganhos que vão se construindo desde a idade mais remota, na relação privilegiada dos bebês com suas mães ou cuidadores, até os anos da pré-escola, numa época em que a influência dos pares se torna mais proeminente.

Verba e Isambert 1983 apud Bondioli \& Mantovani $^{5}$ ( 1998, p.) apresentam pesquisa em que foram investigados os mecanismos de colaboração entre crianças na faixa etária de dois a quatro anos: a colaboração, especialmente em atividades lúdicas (jogos de construção, de regras, de faz-de-conta), em que a criança maior fornece “idéias” e comanda a organização com maior eficácia e responsabilidade; a tutela com ajuda e intervenções (verbais e práticas) por parte do parceiro mais experiente, cabendo à criança menor aceitar ou não a ajuda; o modelo de referência em que o parceiro mais experiente funciona como modelo a ser imitado, nos seus comportamentos e estratégias de resolução de problemas.

Dentro das observações realizadas por Verba e Isambert 1983 apud Bondioli \& Mantovani ${ }^{5}$ (1998, p.), percebe-se que as interações se dão quase que exclusivamente de forma assimétrica, pressupondo ganhos apenas para a criança mais nova. Entretanto, Newman et al. ${ }^{13}$ (1987) ampliam a perspectiva para o entendimento do conceito de zona de desenvolvimento proximal como deflagrador de aprendizagens, introduzindo a noção de zonas de construção. Este conceito pressupõe espaços de trocas dos quais podem emergir aprendizagens em qualquer idade, a partir do compartilhamento e negociação de significados, num movimento de ação recíproca em que ambas as partes se transformam. No jogo, ou ação lúdica, esta idéia tem um sentido essencial pelo fato de que crianças, mais velhas e mais novas, sempre obterão ganhos em seus respectivos papéis e na dinâmica de papéis que se sucedem. São estas relações interpessoais, em muito calcadas no lúdico, que permitem ao ser humano evoluir de um organismo biológico a um membro da cultura, através do desenvolvimento de capacidades somente possíveis pela sua imersão em contextos socioculturais: aquisição da linguagem, pensamento convergente e divergente, sentimento de auto-eficácia, comunicação de expectativas entre os membros da cultura.

As trocas lúdicas que, nos primeiros meses de vida, apresentam-se como um dos elementos constituintes de toda a cognição social, serão ampliadas da esfera do adulto cuidador à esfera dos parceiros, mantendo, para além da infância, um papel de relevância nas interações estabelecidas, assim como nas aprendizagens realizadas pelos seres humanos.

\section{CONCLUSÃO}

A atividade lúdica, que permeia a experiência de desenvolvimento e adaptação do ser humano em todo o seu ciclo de vida, assume importância particular para os estudos realizados nos anos da infância, especialmente nas pesquisas realizadas com bebês, pois desconstrói, ao mesmo tempo, duas crenças que têm se mostrado frágeis nas últimas décadas, exigindo maiores investimentos em sua investigação: a primeira é aquela que colocava o brincar como uma atividade tendo um fim em si mesma, sem importância, desprovida de maiores interesses; a outra é a crença de que os bebês, nos primeiros meses de vida, teriam muito menos competências do que torna-se possível detectar hoje. A qualidade das interações realizadas neste período inicial da vida humana mostrase bastante profícua, impondo aos profissionais uma sofisticação crescente nas formas como criam estratégias de aproximação e entendimento do comportamento dos bebês.

Como apontado por alguns autores, a brincadeira de faz-de-conta, antes tida como uma prerrogativa do alcance da capacidade de simbolizar, também pode ser identificada em sua versão mais embrionária nas interações lúdicas entre adultos e bebês, evidenciando um espaço de construção mediado pelo contato com os membros da cultura, facilitador das funções simbólicas que se sofisticarão em escala crescente com o passar dos anos. As interações lúdicas típicas nas relações estabelecidas entre adultos e bebês não só se apresentam como gênese da brincadeira de faz-de-conta, como lançam os alicerces de toda a cognição social.

Evidencia-se, acima de tudo, a atividade lúdica como uma atividade mediada, potencializadora de aprendizagens sobre si, sobre o os 
objetos, sobre os outros, possibilitando aos sujeitos um meio de experimentação da realidade que os cerca, através do desempenho de papéis, da testagem de hipóteses, da correção de estratégias, num processo de negociação intensa com o mundo físico e o mundo social.

\begin{abstract}
In this article, we examine some contributions of the sociocultural view to the issue of playful activities, focusing on the first relations established by babies with their cultural contexts, through their caretakers. Therefore, it is necessary to briefly approach the conception of zone of proximal development, as well as considerations about playing as a highly important social interaction that is experienced since the child's early years, and constitutes the basis for the construction of very sophisticated learning events throughout life.
\end{abstract}

Key-words: zone of proximal development. game of pretend. caretaker-baby playful activities interactions.

\section{REFERÊNCIAS}

1 Vygotsky LS. A formação social da mente. Rio de Janeiro: Martins Fontes; 1984.

2 Wajskop G. Brincar na pré-escola. São Paulo: Cortez; 2001.

3 Seidl de Moura ML, Ribas AFP. Desenvolvimento e contexto sociocultural: a gênese da atividade mediada nas interações mãe-bebê. Psicol Reflexão Crítica 2000; 13(2): 245-56.

4 Wertsch JV. Sociocultural research in the copyright age. Culture and Psychol 1995; 1(1): 81-102.

5 Bondioli A, Mantovani S. Manual de educação infantil. De 0 a 3 anos. Porto Alegre: Artes Médicas; 1998.

6 Brougère G. A criança e a cultura lúdica. In: 13. Kishimoto TM, organizador. O brincar e suas teorias. São Paulo: Pioneira; 2002.

7 Kishimoto TM, organizador. O brincar e suas teorias. São Paulo: Pioneira; 2002.

8 Benjamin W. Reflexões: a criança, o brinquedo, a educação. São Paulo: Summus; 1984.
9 Bruner J. The nature and the uses of immaturity. Am Psychol 1972; 2(8): 1-22.

10 Rochat P, Striano T. Social-cognitive development in the first year. In: Rochat P. Early social cognition: understending others in the first months of life. Mahwah, N: Lawrence Erlbaum; 1999. p. 3-34.

11 Newson J, Newson E. Toys and playthings. Harmondsworth: Penguin Books; 1979.

12 Tamis-Le Monda CS, Katz JC, Bornstein M. Infant play: functions and partners. In: Slater A, Lewis M, editors. Introduction to infant development. Oxford: Oxford University Press; 2002.

13 Newman D, Griffin P, Cole M. The construction zone: working for cognitive change in school. Cambridge: Cambridge University Press; 1989. 